\title{
A report on the "International Society for Computational Biology - Latin America (ISCB-LA)" Bioinformatics Conference 2016
}

\author{
Nicolas Palopoli12 ${ }^{2}$ Alexander Miguel Monzon', Gustavo Parisi' ${ }^{1}$, Ariel Chernomoretz ${ }^{3}$, Fernán Agüero ${ }^{4}$
}

' Departamento de Ciencia y Tecnología, Universidad Nacional de Quilmes, CONICET, Buenos Aires, Argentina; ${ }^{2}$ Fundación Instituto Leloir-IIBBA-CONICET, Buenos Aires, Argentina; ${ }^{3}$ Integrative Systems Biology Laboratory, Fundacion Instituto Leloir \& IFIBA (FCEN-UBA / CONICET), Buenos Aires, Argentina; ${ }^{4}$ Instituto de Investigaciones Biotecnológicas - Instituto Tecnológico de Chascomús (IIB-INTECH), Universidad Nacional de San Martín (UNSAM) - CONICET, Buenos Aires, Argentina.

\section{Abstract}

The fourth edition of the "International Society for Computational Biology - Latin America (ISCB-LA)" Bioinformatics Conference, jointly organized with the Argentine Association for Bioinformatics and Computational Biology $\left(\mathrm{A}^{2} \mathrm{~B}^{2} \mathrm{C}\right)$, was held in Buenos Aires, Argentina, on November 2016. The ISCB-LA 2016 conference aimed at showcasing the latest findings in the field from researchers at all career levels in the region and beyond, and promoting collaborations to further develop Bioinformatics and Computational Biology in Latin America. Here we present a brief report on the main activities held during the Conference and their successful outcomes.

\section{Introduction}

The 4th edition of the Bioinformatics Conference "International Society for Computational Biology - Latin America (ISCB-LA) ${ }^{1}$ " took place on 21-23 November 2016 at Universidad Católica Argentina (UCA) in Buenos Aires, Argentina. This biennial meeting gathers students and researchers from across Latin America, plus participants and renowned invited speakers from the rest of the world, to present and discuss their work on the development and application of computational methods to advance biological knowledge. More than 300 delegates had the opportunity to network with and learn from colleagues in keynote lectures, selected oral presentations, poster sessions and sponsored tech talks, plus the associated workshop and student symposium.

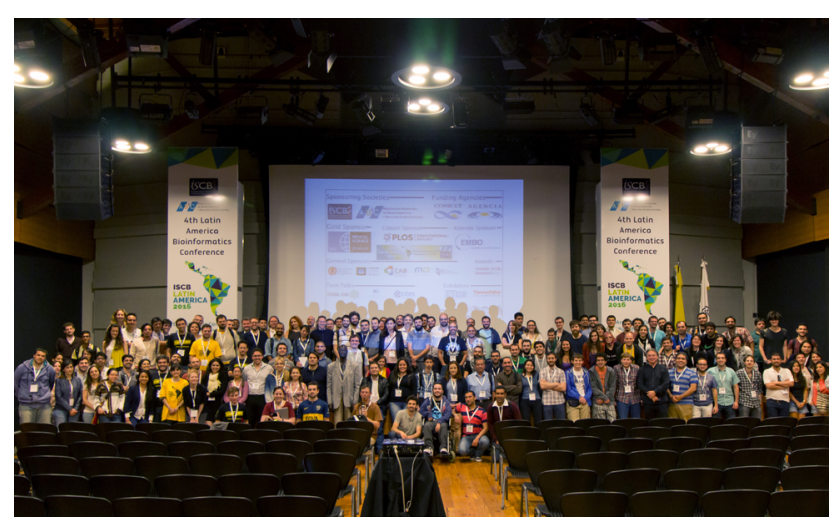

Figure 1. ISCB-LA 2016 conference group photography. Photo by Franco L. Simonetti.
In the last decade, the International Society for Computational Biology ${ }^{2}$ has spread its reach to the scientific communities outside Europe and USA. Latin America has become an active asset for ISCB, as demonstrated by the ISCB-LA meetings and the number of Regional Student Groups (RSG) of the ISCB Student Council $^{3}$ that have flourished lately. Previously joining as conference sponsor, this was the first ISCBLA edition co-organized by the Argentine Association for Bioinformatics and Computational Biology $y^{4}$. It also served as the 7th annual edition of the Argentine Conference on Bioinformatics and Computational Biology. $\mathrm{A}^{2} \mathrm{~B}^{2} \mathrm{C}$ is a non-profit organization established in 2009 that is successfully promoting the growth of Bioinformatics in Argentina and guiding the career development of students and young researchers in the country. In particular, the emergence of $\mathrm{A}^{2} \mathrm{~B}^{2} \mathrm{C}$ has been crucial to create and strengthen bonds between groups working far from each other in a vast country, as well as fostering connections among scientists in Argentina and neighboring countries such as Chile, Uruguay and Brazil.

\section{Main conference}

Highlights of ISCB-LA 2016 were the five keynote lectures presented by invited speakers. Dr. Ruth Nussinov opened the Conference discussing the structural properties of Ras proteins related with cancer development. The day finished with Dr. Emilio Kropff who explained how the internal GPS in a mammalian brain controls the speed 
and displacement of movement, highlighting the special role of the newly discovered speed cells. The second day had Dr. Ana Amador speaking about the use of computational models to predict neural activity of birds based on their singing patterns. It was closed by the EMBO Lecture keynote presentation delivered by Dr. Søren Brunak in which he presented a 20-year-long study on 6 million of Danish patients to uncover correlations among drugs, disease and genetic information. The last keynote, by Dr. Seán I. O’Donoghue, addressed the principles and modern methods available for data visualization, which serve as useful research tools for exploring the huge volume and complexity of current biological data.

Accepted submissions for oral talks were organized in six sessions around a common topic, named "Proteins" (eight talks), "Data" (seven), "Machine Learning" (seven), "Disease" (seven), "Genes" (six) and "Systems" (seven). These comprised presentations by local and international group leaders, early career scientists and $\mathrm{PhD}$ students, selected by senior researchers in the Scientific Committee under the guidance of its Chair, Dr. Morten Nielsen. Also, 221 posters were accepted and split in two afternoon sessions. The presenting authors of the top three posters as chosen by the votes of participants received a cash prize.

Besides the scientific program, there were a couple of social events in the evenings to maximize opportunities of networking. To close the first conference day Dr. Seán O'Donoghue took the stage of the cocktail party to premiere new animations from the VIZBiPlus project ${ }^{5}$. On the last day, the Farewell Party got people together for dinner, drinks and dancing.
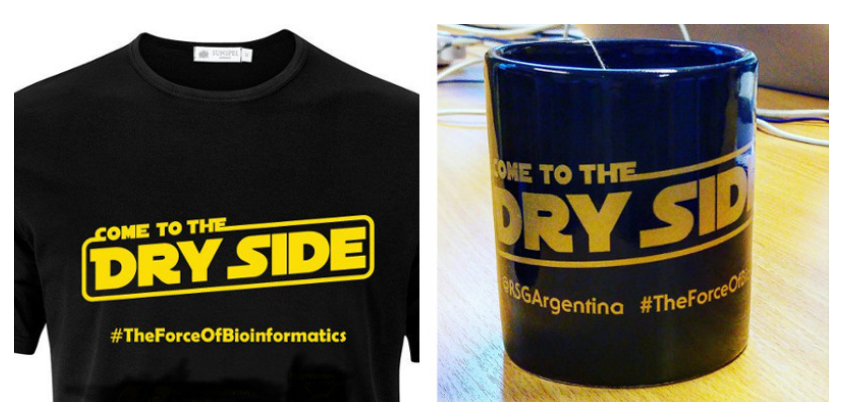

Figure 2. "Come to the dry side", an invitation from the RSGArgentina, printed on merchandise available at ISCB-LA 2016. Photo of the mug by Bart Cuypers.

\section{Satellite activities}

Satellite activities took place on 18-19 November 2016 at Universidad Nacional de San Martín, in Buenos Aires, Argentina. The first day offered the workshop "Data Visualisation Methods and Tools - A Practical Guide"6. Dr. Seán O’Donoghue covered general approaches and computational tools for Data Viz during the morning, followed by a hands-on introduction to the ggplot2 $\mathrm{R}$ library by Alan Bush and Gonzalo Corti Bielsa. On the following day, the second Latin America Student Council Symposium $^{7}$ was attended by 62 delegates who enjoyed 13 student talks and 35 poster presentations. Keynote lectures by Prof. Ruth Nussinov and Dr. Seán O’Donoghue presented their research topics with a special focus on career development advice for young students.

\section{Conclusions}

ISCB-LA 2016 continued the positive trend of support and adhesion it has enjoyed since its inception in $2010^{8}$, highlighting the expanding relevance of Bioinformatics, Computational Biology and related fields in the region. More information about ISCB-LA 2016, including the final schedule and program, is available at: http://www. iscb.org/iscb-latinamerica2016.

\section{Acknowledgements}

We would like to recognize the dedication and support of other members of the local Organising Committee; the ISCB Steering Committee; the Chair and members of the Scientific Committee; the Boards of Directors from $\mathrm{A}^{2} \mathrm{~B}^{2} \mathrm{C}$, ISCB, ISCB-SC and RSG-Argentina; support staff at UCA; and students who acted as volunteers during the conference. We also want to acknowledge the great support we had from funding agencies and conference sponsors.

\footnotetext{
${ }^{5}$ http://vizbi.org/Plus/ ${ }^{6}$ http://lascs2016.iscbsc.org/lascs2016-dataviz-workshop ${ }^{7}$ http://lascs.iscbsc.org ${ }^{8}$ http://www.iscb.org/archive/conferences/iscb/iscb-la2010.html
} 